\title{
Trainability in lexical specificity mediates between short-term memory and both vocabulary and rhyme awareness
}

\author{
Merel M. van Goch ${ }^{\mathrm{a}, \mathrm{b}, *, 1}$, Ludo Verhoeven ${ }^{\mathrm{a}}$, James M. McQueen ${ }^{\mathrm{a}, \mathrm{b}, \mathrm{c}}$ \\ ${ }^{a}$ Radboud University Nijmegen, Behavioural Science Institute, Montessorilaan 3, PO Box 9104, 6500 HE Nijmegen, The Netherlands \\ ${ }^{\mathrm{b}}$ Radboud University Nijmegen, Donders Institute for Brain, Cognition and Behaviour, Geert Grooteplein-Noord 21, PO Box 9010 , 6500 GL Nijmegen, The Netherlands \\ ${ }^{c}$ Max Planck Institute for Psycholinguistics, Wundtlaan 1, PO Box 310, 6500 AH Nijmegen, The Netherlands
}

\section{A R T I C L E I N F O}

\section{Keywords:}

Precursors to literacy

Lexical specificity

Phonological short-term memory

Vocabulary size

Rhyme awareness

\begin{abstract}
A B S T R A C T
A major goal in the early years of elementary school is learning to read, a process in which children show substantial individual differences. To shed light on the underlying processes of early literacy, this study investigates the interrelations among four known precursors to literacy: phonological short-term memory, vocabulary size, rhyme awareness, and trainability in the phonological specificity of lexical representations, by means of structural equation modelling, in a group of 1014 -year-old children. Trainability in lexical specificity was assessed by teaching children pairs of new phonologically-similar words. Standardized tests of receptive vocabulary, short-term memory, and rhyme awareness were used. The best-fitting model showed that trainability in lexical specificity partially mediated between short-term memory and both vocabulary size and rhyme awareness. These results demonstrate that individual differences in the ability to learn phonologicallysimilar new words are related to individual differences in vocabulary size and rhyme awareness.
\end{abstract}

\section{Introduction}

Difficulties in reading and learning to read can cause major problems, for both children and adults. Learning to read is therefore a key goal in the early years of elementary school. Since the process of learning to read involves mapping graphemes onto existing segmental knowledge (used for example in speech processing), a vast amount of research has looked into phonological precursors to literacy, attempting to establish which factors predict successful reading and reading acquisition (Bradley \& Bryant, 1983; De Jong \& Van der Leij, 1999; Ehri et al., 2001). The current study aimed to investigate the relationships between individual differences in four known precursors to literacy, namely, phonological short-term memory, vocabulary size, rhyme awareness, and the ability to learn new words that phonologically differ minimally from each other (what we label as trainability in lexical specificity).

Specifically, this study investigates how trainability in lexical specificity is related to the other precursors, testing the hypothesis that short-term memory predicts vocabulary and rhyming through the mediation of underlying phonological representations. Although it is clear that these four factors predict early literacy, to our knowledge, no previous study has looked at the interrelations among all four of them.
Insight in the underlying interrelations between these predictors to early literacy could, however, shed light on the development of these precursors and hence in the process of learning to read.

Phonological short-term memory capacity is a well-documented precursor to early literacy (Baddeley, 2003; De Jong \& Van der Leij, 1999). A meta-analysis by Swanson, Zheng, and Jerman (2009) showed that children with reading disabilities had more problems with shortterm memory and working memory than average readers. The ability to temporarily store and manage phonological information may be related to literacy in a direct way (Gathercole \& Baddeley, 1993; Torgesen \& Burgess, 1998; Wagner \& Torgesen, 1987), in an indirect way, mediated by other underlying phonological factors (Melby-Lervåg, Lyster, \& Hulme, 2012; Wagner, Torgesen, Laughon, Simmons, \& Rashotte, 1993), or by mediation of the quality of or access to underlying phonological representations (Metsala, 1999).

Second, vocabulary is a predictor of emergent literacy (Verhoeven, Van Leeuwe, \& Vermeer, 2011). Children's vocabulary size predicts print decoding skill (Garlock, Walley, \& Metsala, 2001) and is important for word decoding, visual word recognition, and reading comprehension (Ouellette \& Beers, 2010). Especially before starting kindergarten, children show large individual differences in vocabulary size (StoelGammon, 2011).

\footnotetext{
* Corresponding author at: Utrecht University, Janskerkhof 13, 3512 BL Utrecht, The Netherlands.

E-mail address: m.m.vangoch@uu.nl (M.M. van Goch).

${ }^{1}$ Merel M. van Goch is now working at Liberal Arts and Sciences, Utrecht University.
} 


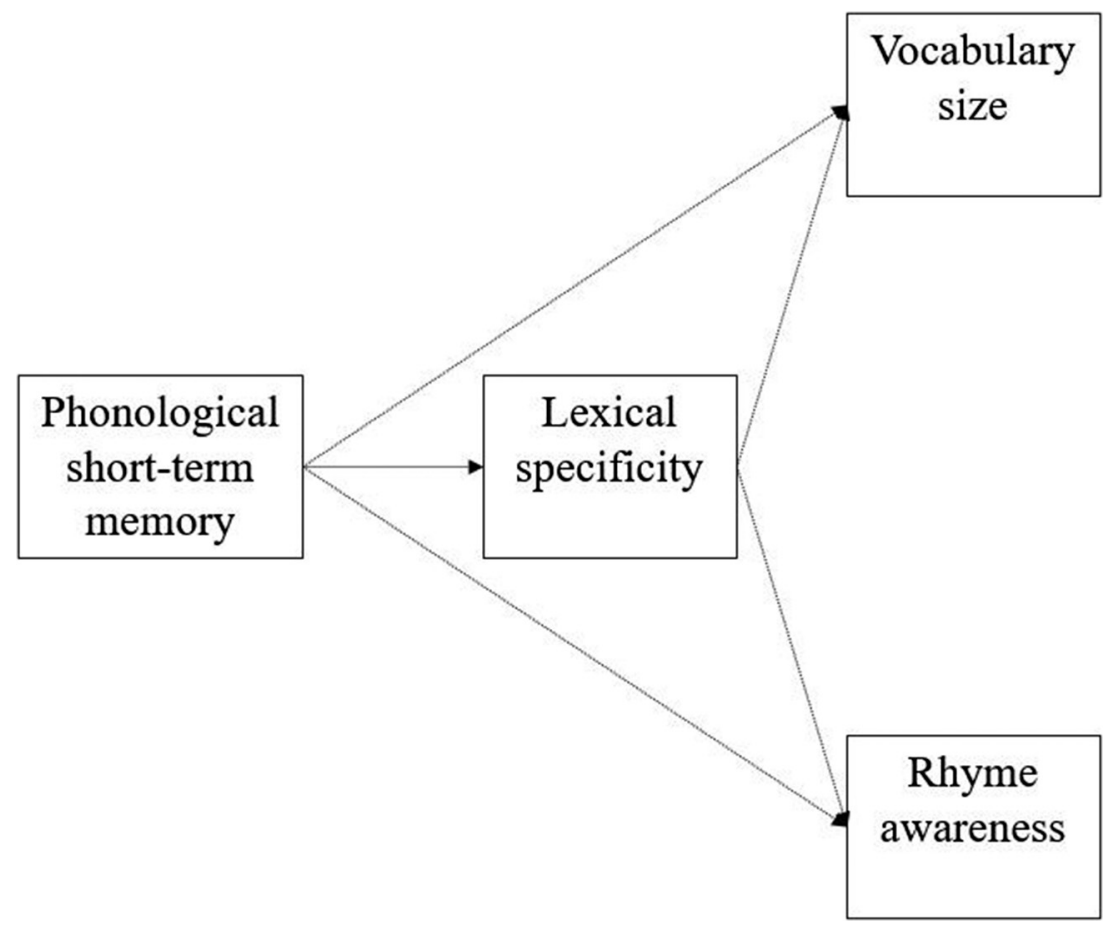

Fig. 1. Hypothetical relations between phonological short-term memory, trainability in lexical specificity, vocabulary size, and rhyme awareness.

A third precursor to literacy is phonological awareness, that is, the ability to consciously reflect upon and manipulate speech sounds. It consists of several subskills (e.g., rhyme awareness and phoneme identification) that develop from awareness of larger to smaller sound units, and is an important predictor of emergent literacy in alphabetic orthographies (Anthony, Lonigan, Driscoll, Phillips, \& Burgess, 2003; Bradley \& Bryant, 1983; Ehri et al., 2001; Stanovich, 1992; Vloedgraven \& Verhoeven, 2007; Ziegler \& Goswami, 2005). For example, success in learning to read is predicted by rhyme awareness before formal reading education (Bradley \& Bryant, 1983).

Fourth and finally, the phonological specificity of representations in the mental lexicon and, relatedly, the ability to learn minimally different new words influences print decoding skill and emergent literacy (Elbro, Borstrøm, \& Petersen, 1998; Fowler, 1991; Metsala \& Walley, 1998; Van Goch, McQueen, \& Verhoeven, 2014). Furthermore, variation in the quality of word representations has been shown to influence reading skill (Perfetti, 2007).

These four precursors interact with each other and hence both independently and jointly contribute to the process of learning to read. For example, training lexical specificity by teaching children new words that phonologically differ minimally from each other, fosters phonological awareness (Janssen, Segers, McQueen, \& Verhoeven, 2015; Van Goch et al., 2014). Garlock et al. (2001) showed that phonological awareness, receptive vocabulary and phonological short-term memory contributed to word reading. In particular, vocabulary size predicted print decoding skill and phonological awareness, and the latter in turn also predicted print decoding skill (Garlock et al., 2001). In a study on predicting dyslexia from kindergarten, Elbro et al. (1998) showed that phonological awareness predicted print decoding skill, and lexical specificity predicted both phonological awareness and print decoding skill. Gathercole and Baddeley (1993) showed that phonological shortterm memory is related to vocabulary and reading acquisition. Furthermore, in a longitudinal study with Dutch children, phonological awareness predicted reading acquisition, and phonological short-term memory predicted phonological awareness (De Jong \& Van der Leij, 1999). Rispens and Baker (2012) showed that phonological short-term memory and lexical specificity both contributed to non-word repetition, which is associated with vocabulary and literacy (ContiRamsden \& Durkin, 2007; Gathercole, 2006). Another important aspect of these precursors is that they develop over time. These skills are not static, and their development is prolonged: vocabulary size and memory capacity expand, phonological awareness increases and becomes more detailed, and, through the process of lexical restructuring, lexical representations become more specified. Again, the development of these skills, and their individual and joint influence on reading acquisition, co-occurs and co-exists.

This study asks how the development of these precursors is interrelated. Previous evidence is inconclusive about the correlational relationships among these precursors in 4-year-olds. For example, as discussed earlier, short-term memory predicts vocabulary size and rhyme awareness. However, the specificity of phonological representations likely plays a role in this relation. According to lexical restructuring theories (Metsala \& Walley, 1998; Munson, Edwards, \& Beckman, 2011; Stoel-Gammon, 2011), increasing vocabulary size leads to increasingly specified lexical representations, which leads to phoneme awareness. Indeed, lexical specificity training fosters different aspects of phonological awareness (Janssen et al., 2015; Van Goch et al., 2014). The lexical restructuring process is believed to continue into elementary school years. However, studies with younger children suggest that lexical restructuring is a process that occurs earlier in development, before children learn to read. Moreover, the evidence that lexical specificity predicts phonological awareness suggests that an important part of lexical restructuring happens in early childhood. For example, six-year-olds already have detailed and abstract phonological representations (McQueen, Tyler, \& Cutler, 2012). At an even earlier age, toddlers show sensitivity for fine-grained differences in the pronuncia- 
tion of words (Swingley \& Aslin, 2000; White \& Morgan, 2008) and flexibility in their interpretation of phonological detail (White \& Aslin, 2011), both suggesting that their lexical representations are specified to a certain extent.

The current study was thus set up to investigate the role of trainability in lexical specificity in 4-year-olds showing typical language development. It explored the relationships among trainability in lexical specificity (i.e., the ability to learn phonologically specified lexical representations), phonological short-term memory, vocabulary size and rhyme awareness (see Fig. 1). Rhyme awareness was used to assess phonological awareness, because lexical specificity training fostered rhyme awareness in the study by Van Goch et al. (2014), and because at this age, other phonological awareness measures might be too difficult and thus unreliable. In particular, we tested whether phonological short-term memory indeed predicted trainability in lexical specificity, vocabulary and rhyme awareness.

Our main question was whether trainability in lexical specificity predicts rhyme awareness and vocabulary, and thus, whether trainability in lexical specificity either fully or partially mediates between short-term memory and early literacy. First, the ability to learn phonologically specific new words was hypothesized to predict rhyme awareness, because having representations specified at the level of phonemic differences should make it easier to learn to manipulate phonemes, and because lexical specificity training has been found to foster rhyme awareness (Van Goch et al., 2014). Second, trainability in lexical specificity was hypothesized to predict vocabulary size, because being able to learn phonologically specific representations and the ability to discriminate between them should facilitate the acquisition of new words, hence leading to a larger vocabulary. Third, based on previous research, phonological short-term memory ability was hypothesized to predict rhyme awareness and receptive vocabulary (Baddeley, 2003). Phonological short-term memory was also hypothesized to predict trainability in lexical specificity, because phonological short-term memory capacity is necessary to remember and integrate the sound structure of newly learned words adequately. These predictions are summarized in Fig. 1.

In addition to models testing these relationships, alternative models were considered. Two models in which vocabulary size predicts trainability in lexical specificity (i.e., the reverse relationship) were also assessed, since lexical restructuring accounts suggest that increasing vocabulary size leads to increasingly segmental representations (Metsala \& Walley, 1998), which could imply that increasing vocabulary size might lead to the ability to learn phonologically specific new words, in turn leading to increasingly segmental representations.

This study adds to the existing literature in several ways. First, it explores the influence of lexical specificity training on vocabulary. The relation between lexical specificity training and phonological awareness has been shown (Janssen et al., 2015; Van Goch et al., 2014), but it is not clear whether teaching children phonologically-similar words also fosters vocabulary development. Although the process of lexical restructuring and the concept of lexical specificity have been studied to some extent (Janssen et al., 2015; Van Goch et al., 2014), the correlations between known precursors to literacy and the trainability of lexical specificity as a means of boosting the process of lexical restructuring have not been studied thoroughly yet. Second, this study investigates interrelations between precursors at one time point: the start of kindergarten. Most studies are causal and longitudinal, focusing on precursors for reading problems, instead of correlational aspects of normal language development, and hence study children that are older than 4 years (De Jong \& Van der Leij, 1999;Elbro et al., 1998; Goswami, 2000). However, to understand hampered language development,
Table 1

Examples of stimulus quadruplets used in the trainability in lexical specificity task.

\begin{tabular}{llllll}
\hline $\begin{array}{l}\text { Unfamiliar } \\
\text { target A }\end{array}$ & $\begin{array}{l}\text { Unfamiliar } \\
\text { target B }\end{array}$ & $\begin{array}{l}\text { Unfamiliar } \\
\text { control }\end{array}$ & $\begin{array}{l}\text { Familiar } \\
\text { control }\end{array}$ & Contrast type & $\begin{array}{l}\text { Contrast } \\
\text { position }\end{array}$ \\
\hline luit & ruit & kuit & huid & Manner & Initial \\
bar & dar & war & kar & Place & Initial \\
pas & bas & gas & jas & Voice & Initial \\
pol & pon & pos & pop & Manner & Final \\
raap & raat & raaf & raam & Place & Final \\
\hline
\end{tabular}

knowledge about interrelations in normal language development and the early stages of literacy acquisition is crucial. Using structural equation modelling made it possible to study interrelations between individual differences in the factors we measured. Third, the study uses a trainability in lexical specificity task in which children learn phonologically-similar words. Previous studies often used production measures instead of perception or metalinguistic measures to study the specificity of lexical representations (Elbro et al., 1998; Goswami, 2000), even though new words are learned initially through perception, rather than through production (Laufer, 1998). The task used here provides a measure of how easily children can learn words that are minimally different and hence their ability to form phonologically specific lexical representations.

In summary, in order to gain insight into individual differences in the process of learning to read, the current study aimed to investigate the relations among trainability in lexical specificity, phonological short-term memory, vocabulary size and rhyme awareness in 4-yearolds showing normal language development.

\section{Method}

\subsection{Participants}

A group of 101 children (55 male, $M_{\text {age }}=50.46$ months, age range: 47-54 months) participated. The children were randomly selected from six elementary schools in one municipality in the south of the Netherlands. At the time of testing, all children attended the first year (of two years) of kindergarten and had not yet received formal reading education. All children were monolingual, native speakers of Dutch and did not have any known developmental or language-related problems, according to their teachers and/or parents.

\subsection{Materials}

\subsubsection{Trainability in lexical specificity}

To measure trainability in the phonological specificity of lexical representations, a word learning game was used (cf. Van Goch et al., 2014). In this game, children learned pairs of new words, which differed minimally from each other. The game consisted of a training phase, in which the new words were taught, and a test phase.

Quadruplets of monosyllabic Dutch words were made (examples of stimulus quadruplets are given in Table 1; all quadruplets can be found in Van Goch et al., 2014), consisting of two unfamiliar target words that differed on one acoustic-phonetic feature (e.g., raap [turnip] and raat [honeycomb] differ in place of articulation), an unfamiliar control word (e.g., raaf [raven]) and a familiar control word (e.g., raam [window]), both differing on two acoustic-phonetic features with both target words. Stimulus familiarity was assessed using the Basic Vocabulary of Kindergartners in Amsterdam test (Mulder, Timman, \& Verhallen, 


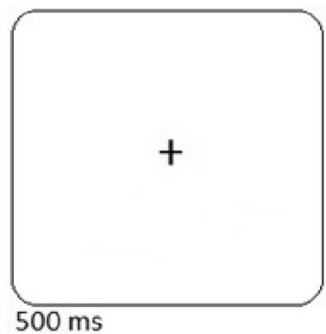

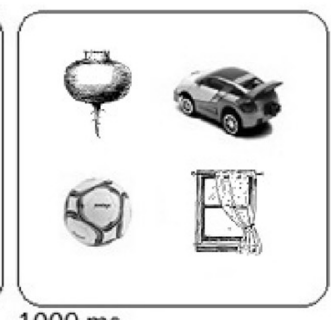

$1000 \mathrm{~ms}$

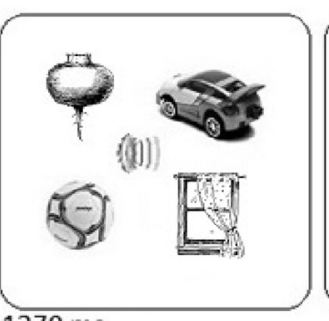

$1379 \mathrm{~ms}$

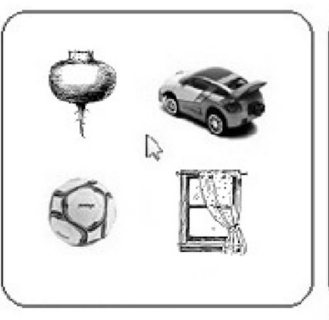

$1000 \mathrm{~ms}$

Fig. 2. Trial design for the Lexical Specificity task, for a trial in the first block of the task.

Table 2

Design and stimulus examples of the lexical specificity task.

\begin{tabular}{lll}
\hline Block & Experimental items & Example \\
\hline 1. Training phase & Unfamiliar target word A & $\begin{array}{l}\text { raap } \text { [turnip] } \\
\text { Faam } \text { [window] }\end{array}$ \\
2. Training phase & Unfamiliar control word & raat [honeycomb] \\
& Familiar control word B & raam [window] \\
3. Training phase & Unfamiliar target word A & raarnip] \\
& Unfamiliar control word & raat [honeycomb] \\
4. Training phase & Unfamiliar target word B & raaf [raven] \\
& Unfamiliar control word & raap [turnip] \\
5. Test phase & Unfamiliar target word A & raaneycomb] \\
& Unfamiliar target word B & \\
\end{tabular}

2009).

Contrast position and type were manipulated. In total, there were 24 quadruplets, in 16 of which the contrast was on the initial phoneme, whereas in 8 the contrast was on the final phoneme. Furthermore, of the 24 quadruplets, 13 involved a contrast in manner of articulation, 7 a contrast in place of articulation, and 4 a contrast in voicing.

The words were taught to the children by means of pictures and auditory stimuli. Every trial started with a fixation cross, after which the children saw four pictures (see Fig. 2). Of these four response alternatives, two were highly frequent and highly familiar pictures, which were not related (either phonologically or semantically) to the target pictures, and the other two were the experimental items (see Table 2). Then the children heard one auditory question containing only one of two target words of a stimulus quadruplet (e.g., What do you think is a raap?) after which the children gave a response using the computer mouse. There was positive feedback (a picture of a friendly clown) if the response was correct, but no feedback in the case of an incorrect response.

The task consisted of five blocks (see Table 2). Over the course of the task, the difficulty of the task increased gradually, in two ways, by means of the experimental items used as response alternatives. In the first part of the task, the target words were paired with the familiar control word, with a two-feature difference. The latter part of the task consisted of only unfamiliar words, first with a two-feature difference and then with a one-feature difference. Within blocks, the order of the quadruplets was randomized and contrast type (manner, place, voice), contrast position (initial, final) and position of the target on the screen were pseudo-randomized.

In total, the task consisted of 134 trials: 5 practice trials (in which the strategy was explained), 124 experimental trials, and 9 highly frequent and familiar fillers. The task took $20 \mathrm{~min}$ on average. The score on this task was the percentage of correctly recognized words. A score was calculated for the test phase only, and a composite score was calculated for the training and test phases together. Since these scores correlated highly with each other (Pearson's $\mathrm{r}=0.78 ; p<0.01$ ), analyses were done with the combined score for the training and test phases, to increase power. Cronbach's alpha for this task was 0.60.

\subsubsection{Rhyme awareness}

Rhyme awareness, as a measure of phonological awareness, was assessed by means of the rhyme awareness task of the standardized Diagnostic Instrument for Emergent Literacy (Vloedgraven, Keuning, \& Verhoeven, 2009). In this task, three response alternatives were shown and named, e.g., hoed [hat], bal. [ball], peer [pear]. Given an auditory question containing a target word, e.g., wat rijmt op beer? [what rhymes with bear?], the child was required to indicate which word rhymed with the target word. All stimuli were highly frequent monosyllabic Dutch words. The task consisted of two practice trials and 15 experimental trials. The percentage of correctly answered trials was the score on this task. Reliability for this standardized instrument is good: Cronbach's alpha > 0.90 (Vloedgraven et al., 2009).

\subsubsection{Receptive vocabulary}

To assess receptive vocabulary size, the standardized Receptive Vocabulary task of the Dutch Language Test for Children (Verhoeven \& Vermeer, 2006) was administered. In this task, given an auditory target word, children were asked to indicate the target picture (e.g., neus [nose]) among four response alternatives (e.g., neus, knie [knee], huis [house], poes [cat]). The task consisted of 96 trials, but was brought to an end in advance if five consecutive errors were made. The score on this task was the sum of all correctly answered trials. Reliability of this standardized task is good, with a Cronbach's alpha of 0.97 (Verhoeven \& Vermeer, 2006).

\subsubsection{Phonological short-term memory}

Phonological short-term memory was assessed using the serial recall task Memory from the standardized Test for Language Problems (Verhoeven, 2005). In the first part of the task, children were asked to repeat series of unrelated words, e.g., wip [seesaw], pet [cap], tak [branch]. The series increased in length over the course of the task. For this part, scoring consisted of one point per correctly recalled trial. In the second part of the task, children were asked to repeat sentences, e.g., de oude man zat op een bank [the old man sat on a couch], which increased in length and complexity over the course of the task. For this part, children received two points when the sentence was recalled correctly, one point when the meaning of the sentence was recalled correctly, and zero points in other cases. Either part of the task was brought to an end when three consecutive trials were repeated incorrectly. The two subtasks correlated highly with each other $(p<0.01)$. Therefore, in the analyses, the sum of the scores on the 
Table 3

Descriptive statistics $(N=101)$.

\begin{tabular}{lll}
\hline Variable & M (SD) & Possible range \\
\hline Age $^{\mathrm{a}}$ & $50.46(1.967)$ & $\mathrm{n} / \mathrm{a}$ \\
Phonological Short-Term Memory $^{\mathrm{b}}$ & $11.13(3.791)$ & $1-36$ \\
Rhyme Awareness $^{\mathrm{c}}$ & $61.32(18.234)$ & $1-100$ \\
Receptive Vocabulary $^{\mathrm{d}}$ & $41.75(12.658)$ & $1-96$ \\
Lexical Specificity Trainability $^{\mathrm{e}}$ & $38.16(12.357)$ & $1-100$ \\
\hline
\end{tabular}

\section{a In months.}

${ }^{\mathrm{b}}$ Sum of the number of correctly recalled word series and twice the number of correctly recalled sentences.

${ }^{\mathrm{c}}$ Percentage correct trials (chance $=33 \%$ ).

d Percentage correct trials.

e Percentage correct trials (chance $=25 \%$ ).

Table 4

Correlations between variables of children's performance $(N=101)$.

\begin{tabular}{llllll}
\hline & 1 & 2 & 3 & 4 & 5 \\
\hline 1. Age & - & & & & \\
2. Phonological short-term memory & 0.184 & - & & & \\
3. Rhyme awareness & 0.076 & $0.379^{* * *}$ & - & & \\
4. Receptive vocabulary & $0.323^{* *}$ & $0.390^{* *}$ & $0.227^{*}$ & - & \\
5. Lexical specificity & $0.239^{*}$ & $0.215^{*}$ & $0.267^{* *}$ & $0.287^{* * *}$ & - \\
\hline
\end{tabular}

$$
{ }^{*} p<0.05 \text {. }
$$$$
\text { ** } p<0.01 \text {. }
$$

two subtasks was used as the score for phonological short-term memory. This task has good reliability: Cronbach's alpha is 0.88 (Verhoeven, 2005).

\subsection{Procedure and data analyses}

Children were tested individually in a quiet room in their schools. Tasks were administered in a fixed order (that is, phonological shortterm memory, passive vocabulary, rhyme awareness, lexical specificity). In the tasks that were administered on a computer, the participants listened to the stimuli via headphones. The volume was always kept constant, for all tasks and for all participants.

After data exploration (which revealed no missing data and/or outliers), structural equation modelling (SEM) was used to analyse the relations between the measures. Path models were estimated in Lisrel (Jöreskog \& Sörbom, 1996). The goodness of fit of the models was assessed by: $\chi^{2}$, Standardized Root Mean Square Residual (SRMR), Comparative Fit Index (CFI), and Root Mean Square Error of Approximation (RMSEA). In SEM analyses, a model is considered to fit well if the chi-square test is non-significant $(p>0.05)$, SRMR is below 0.08 , CFI is above 0.90 (Bentler \& Bonett, 1980) and RMSEA is below 0.08 (Hu \& Bentler, 1999). Although RMSEA is likely not reliable in models with low df (Kenny, Kaniskan, \& McCoach, 2015), which is the case in our models, we include RMSEA for completeness.

\section{Results}

\subsection{Descriptive statistics and correlations}

The descriptive statistics of all measures are shown in Table 3. It was possible to assess whether children performed significantly above chance only for the Rhyme Awareness and Lexical Specificity Trainability tasks. This was the case for both tasks. As can be seen in Table 4, all performance measures correlated significantly with each other.

\subsection{Structural equation modelling}

First, a path model testing the interrelations between Phonological Short-Term Memory, Vocabulary Size, and Rhyme Awareness scores was assessed (Fig. 3a). All interrelations were significant $(p<0.05)$. The model provided a close fit and was a good model for the data $\left(\chi^{2}(1\right.$, $N=101)=0.86, \quad p=0.353, \quad$ SRMR $=0.032, \quad$ CFI $=1.00$, RMSEA $=0.00$, RMSEA 90\% CI $=0.0 ; 0.26$ ).

Second, a model testing the relationships between Lexical Specificity, Vocabulary Size, and Rhyme Awareness scores was assessed (Fig. 3b). Although all relations were significant $(p<0.05)$, the fit indices indicated that this model fitted less well than the previous model $\quad\left(\chi^{2}(1, \quad N=101)=2.65, \quad \mathrm{p}=0.103, \quad\right.$ SRMR $=0.061$, $\mathrm{CFI}=0.90$, RMSEA $=0.13$, RMSEA $90 \% \mathrm{CI}=0.0 ; 0.33$ ).

Finally, the two previous models were combined in a third model, testing the relations between the scores for all four factors (Fig. 3c). The results of this model showed that all relations were significant $(\mathrm{p}<0.05)$, that it provided a close fit to the data, and hence was a good model $\left(\chi^{2}(1, \quad N=101)=0.24, \quad \mathrm{p}=0.63, \quad\right.$ SRMR $=0.013$, $\mathrm{CFI}=1.00$, RMSEA $=0.00$, RMSEA $90 \% \mathrm{CI}=0.0 ; 0.21$ ). Given the fit indices, the model provided a better fit than the two previous models (see Table 5). This final model explained $5 \%$ of the variance in Lexical Specificity, $15 \%$ of the variance in Vocabulary size, and $18 \%$ of the
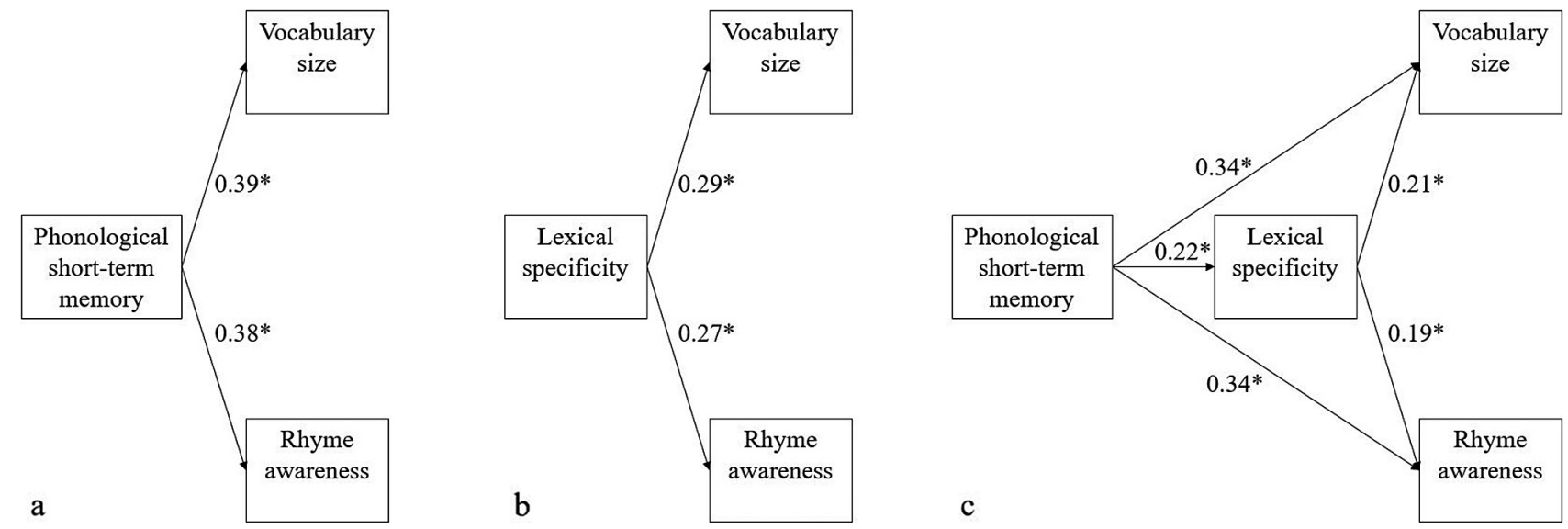

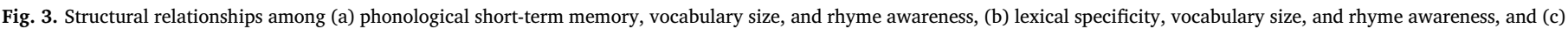
phonological short-term memory, lexical specificity, vocabulary size, and rhyme awareness $(N=101)$. Note. Numbers indicate standardized Beta Coefficients. * $p<0.05$. 


\begin{tabular}{lllllll}
\hline & Model 3a & Model 3b & Model 3c & Alternative model 1 & Alternative model 2 & Alternative model 3 \\
\hline $\mathrm{p}$ & 0.353 & 0.103 & 0.630 & 0.03 & 0.06 & 0.55 \\
$\chi^{2}$ & 0.86 & 2.65 & 0.24 & 4.68 & 3.61 & 0.36 \\
SRMR & 0.032 & 0.061 & 0.013 & 0.082 & 0.053 & 0.012 \\
CFI & 1.00 & 0.90 & 1.00 & 0.78 & 0.95 & 0.00 \\
RMSEA & 0.00 & 0.13 & 0.00 & 0.19 & 0.16 & 0.00 \\
RMSEA 90\% CI & $0.0 ; 0.26$ & $0.0 ; 0.33$ & $0.0 ; 0.21$ & $0.048 ; 0.38$ & $0.0 ; 0.36$ & $0.0 ; 0.22$ \\
\hline
\end{tabular}

variance in Rhyme Awareness. It showed that Phonological Short-Term Memory predicted Vocabulary Size, Lexical Specificity, and Rhyme Awareness. Furthermore, Lexical Specificity predicted Vocabulary Size and Rhyme Awareness. Thus, Lexical Specificity partially mediated between Phonological Short-Term Memory and both Vocabulary Size and Rhyme Awareness.

In addition, alternative models were assessed. First, a model testing whether Vocabulary Size predicted Lexical Specificity and Rhyme Awareness was assessed. Although all relations were significant, this model did not provide a good fit $\left(\chi^{2}(1, N=101)=4.68, \mathrm{p}=0.03\right.$, SRMR $=0.082, \quad$ CFI $=0.78, \quad$ RMSEA $=0.19, \quad$ RMSEA $\quad 90 \%$ $\mathrm{CI}=0.048 ; 0.38)$. A second alternative model tested whether Vocabulary Size (partially) mediated between Phonological ShortTerm Memory and Lexical Specificity and Rhyme Awareness. Not all relations were significant and this model did not provide a good fit $\left(\chi^{2}(1, \quad N=101)=3.61, \quad \mathrm{p}=0.06, \quad \mathrm{SRMR}=0.053, \quad \mathrm{CFI}=0.95\right.$, RMSEA $=0.16$, RMSEA $90 \% \mathrm{CI}=0.0 ; 0.36)$. Because Age correlated significantly with Vocabulary and Lexical Specificity, a third alternative model added Age as a predictor to the original final model. This alternative model provided a good fit $\left(\chi^{2}(1, N=101)=0.36\right.$, $\mathrm{p}=0.55$, SRMR $=0.012$, CFI $=1.00$, RMSEA $=0.00$, RMSEA $90 \%$ $\mathrm{CI}=0.0 ; 0.22$ ), but not all relations were significant. Because these alternative models did not fit or did not fit as well as the original models, the final model of the original analysis was considered to be the best model.

\section{Discussion}

The current study investigated the links between individual differences in trainability in lexical specificity, phonological short-term memory, vocabulary size and phonological awareness, by means of structural equation modelling. The results showed that, as predicted, phonological short-term memory capacity explained variance in both vocabulary size and rhyme awareness. Furthermore, the ability to learn phonologically specific new words explained variance in vocabulary size and phonological awareness. Importantly, the best-fitting model showed that trainability in lexical specificity partially mediated between phonological short-term memory, on the one hand, and vocabulary size and rhyme awareness, on the other.

The ability to learn new words that phonologically differ minimally was assessed using a trainability in lexical specificity task. This training task tapped into two distinct, but related, skills. First, it assessed the ability to learn new words (which, we suggest, is why performance on this task influences vocabulary size). Second, it assessed the ability to distinguish between phonologically related new words (which, we suggest, is why performance on this task also predicts rhyme awareness). On average, children learned $38 \%$ of the new words in the training task. The ability to learn new words logically leads to a larger vocabulary size, as more new representations can be learned and stored. The ability to specify the sound structure of these new representations aids in the ability to recognize them, and hence aids in the ability to discriminate between different representations. In turn, the ability to learn minimal pairs of new words depends on the ability to distinguish the small phonological differences between the words. This ability, driven by phonologically specified lexical representations, in turn facilitates phonological awareness. Indeed, children who were better in learning the new phonologically-similar words also scored better on the rhyme awareness task. This is in line with previous research on the link between phonologically specified lexical representations and phonological awareness (Elbro \& Jensen, 2005; Elbro et al., 1998; Fowler, 1991; Van Goch et al., 2014). Subsequently, as vocabulary size increases, the underlying lexical representations become more specified (Metsala \& Walley, 1998; Stoel-Gammon, 2011). An alternative model testing whether vocabulary size explained variance in trainability in lexical specificity provided a poorer fit than our original model, therefore challenging lexical restructuring accounts (Metsala \& Walley, 1998).

As expected, the current results showed that phonological shortterm memory predicted lexical specificity, vocabulary size and phonological awareness. Again, this stresses the importance and influence of phonological short-term memory in early childhood, as previously shown by studies relating memory capacity to, among others, reading, vocabulary, arithmetic, and school success (Baddeley, 2003; De Jong \& Van der Leij, 1999; Gathercole \& Baddeley, 1993; Swanson et al., 2009).

Since this study only investigated correlations between factors, future research could use training paradigms to examine whether the development of these factors can be boosted through intervention. For example, learning phonologically specific new words fosters phonological awareness in 4.5-year-old monolingual children (Van Goch et al., 2014) and bilingual children (Janssen et al., 2015). The current study is a first attempt to unravel the relationships between individual differences in trainability in lexical specificity, phonological short-term memory, and early literacy, in 4-year-olds. Since all precursors to literacy were measured in the first year of kindergarten only, and this was thus a cross-sectional study, the present results should be interpreted with caution. Another limitation of the current study is the use of single measures on each skill, for example the use of rhyme awareness as the sole measure of phonological awareness. To shed light on the causal relations between these precursors and their predictive influence on literacy, that is, to improve or expand the model proposed in the current study, future research should be longitudinal, include multiple measures on each skill, and include measures of emerging literacy (e.g., letter knowledge or print decoding in the older children).

In kindergarten and the early years of primary school, important goals are to increase children's vocabulary size and enhance their phonological awareness. Children show substantial individual differences in the development of early literacy. The current study shows that these individual differences are related to phonological short-term memory capacity and the ability to learn phonologically specific new words. This indicates that to improve these early literacy skills, attention could be paid not only to short-term memory, but also to learning words that are phonologically similar. We suggest that this could be done by teaching children new words with minimal acousticphonetic differences using a lexical specificity training protocol (Janssen et al., 2015; Van Goch et al., 2014). Knowledge of differences among children could be used to improve assessment and intervention of language and reading problems in early primary school.

To conclude, the current study examined the role of the ability to learn words that are phonologically-similar as a precursor to early 
literacy in 4-year-olds showing typical language development, by assessing interrelations between trainability in lexical specificity and three precursors to literacy. The study replicated findings that shortterm memory is related to vocabulary and phonological awareness. The most important new finding was that individual differences in learning phonologically specific new words partially mediate the relationship between phonological short-term memory and both vocabulary and phonological awareness.

\section{References}

Anthony, J. L., Lonigan, C. J., Driscoll, K., Phillips, B. M., \& Burgess, S. R. (2003). Phonological sensitivity: A quasi-parallel progression of word structure units and cognitive operations. Reading Research Quarterly, 38(4), 470-487.

Baddeley, A. (2003). Working memory: Looking back and looking forward. Nature Reviews Neuroscience, 4(10), 829-839. http://dx.doi.org/10.1038/nrn1201.

Bentler, P. M., \& Bonett, D. G. (1980). Significance tests and goodness of fit in the analysis of covariance structures. Psychological Bulletin, 88(3), 588.

Bradley, L., \& Bryant, P. (1983). Categorizing sounds and learning to read - a causal connection. Nature, 301, 419-421.

Conti-Ramsden, G., \& Durkin, K. (2007). Phonological short-term memory, language and literacy: Developmental relationships in early adolescence in young people with SLI. Journal of Child Psychology and Psychiatry, 48(2), 147-156.

De Jong, P., \& Van der Leij, A. (1999). Specific contributions of phonological abilities to early reading acquisition: Results from a Dutch latent variable longitudinal study. Journal of Educational Psychology, 91(3), 450-476.

Ehri, L. C., Nunes, S. R., Willows, D. M., Schuster, B. V., Yaghoub-Zadeh, Z., \& Shanahan, T. (2001). Phonemic awareness instruction helps children learn to read: evidence from the national reading panel's meta-analysis. Reading Research Quarterly, 36(3), 250-287. http://dx.doi.org/10.1598/rrq.36.3.2.

Elbro, C., Borstrøm, I., \& Petersen, D. K. (1998). Predicting dyslexia from kindergarten: the importance of distinctness of phonological representations of lexical items. Reading Research Quarterly, 33(1), 36-60. http://dx.doi.org/10.1598/rrq.33.1.3.

Elbro, C., \& Jensen, M. N. (2005). Quality of phonological representations, verbal learning, and phoneme awareness in dyslexic and normal readers. Scandinavian Journal of Psychology, 46, 375-384.

Fowler, A. (1991). How early phonological development might set the stage for phoneme awareness. Haskins Laboratories Status Report on Speech Research, SR-105, 53-64.

Garlock, V. M., Walley, A. C., \& Metsala, J. L. (2001). Age-of-acquisition, word frequency, and neighborhood density effects on spoken word recognition by children and adults. Journal of Memory and Language, 45(3), 468-492. http://dx.doi.org/10.1006/jmla. 2000.2784.

Gathercole, S. E. (2006). Nonword repetition and word learning: The nature of the relationship. Applied PsychoLinguistics, 27, 513-543.

Gathercole, S. E., \& Baddeley, A. D. (1993). Phonological working memory: A critical building block for reading development and vocabulary acquisition? European Journal of Psychology of Education, 8(3), 259-272.

Goswami, U. (2000). Phonological representations, reading development and dyslexia: Towards a cross-linguistic theoretical framework. Dyslexia, 6(2), 133-151. http://dx doi.org/10.1002/(SICI)1099-0909(200004/06)6:2 <133::AID-DYS160>3.0.CO;2-A.

Hu, L. T., \& Bentler, P. M. (1999). Cutoff criteria for fit indexes in covariance structure analysis: Conventional criteria versus new alternatives. Structural Equation Modeling: A Multidisciplinary Journal, 6(1), 1-55.

Janssen, C., Segers, E., McQueen, J. M., \& Verhoeven, L. (2015). Lexical specificity training effects in second language learners. Language Learning, 65(2), 358-389.

Jöreskog, K. G., \& Sörbom, D. (1996). LISREL 8: User's reference guide: Scientific Software International.

Kenny, D. A., Kaniskan, B., \& McCoach, D. B. (2015). The performance of RMSEA in models with small degrees of freedom. Sociological Methods \& Research, 44(3), 486-507.

Laufer, B. (1998). The development of passive and active vocabulary in a second language: Same or different? Applied Linguistics, 19(2), 255-271.

McQueen, J. M., Tyler, M. D., \& Cutler, A. (2012). Lexical retuning of children's speech perception: Evidence for knowledge about words' component sounds. Language Learning and Development, 8, 317-330.

Melby-Lervåg, M., Lyster, S. A. H., \& Hulme, C. (2012). Phonological skills and their role in learning to read: a meta-analytic review. .

Metsala, J. L. (1999). Young children's phonological awareness and nonword repetition as a function of vocabulary development. Journal of Educational Psychology, 91(1), 3.

Metsala, J. L., \& Walley, A. C. (1998). Spoken vocabulary growth and the segmental restructuring of lexical representations: Precursors to phonemic awareness and early reading ability. In J. L. Metsala, \& L. C. Ehri (Eds.), Word recognition in beginning literacy. Mahwah, NJ: Lawrence Erlbaum Associates Publishers.

Mulder, F., Timman, Y., \& Verhallen, S. (2009). Basiswoordenlijst Amsterdamse Kleuters.

Munson, B., Edwards, J., \& Beckman, M. E. (2011). Phonological representations in language acquisition: Climbing the ladder of abstraction. In A. C. Cohn, C. Fougeron, \& M. K. Huffman (Eds.), The Oxford handbook of laboratory phonology (pp. 288-309). Oxford: Oxford University Press.

Ouellette, G., \& Beers, A. (2010). A not-so-simple view of reading: How oral vocabulary and visual-word recognition complicate the story. Reading and Writing, 23, 189-208.

Perfetti, C. (2007). Reading ability: Lexical quality to comprehension. Scientific Studies of Reading, 11(4), 357-383.

Rispens, J., \& Baker, A. (2012). Nonword repetition: The relative contributions of phonological short-term memory and phonological representations in children with language and reading impairment. Journal of Speech, Language, and Hearing Research, 55(3), 683-694.

Stanovich, K. E. (1992). Speculations on the causes and consequences of individual differences in early reading acquisition. In L. E. E. P. B. Gough, \& R. Treiman (Eds.), Reading acquisition (pp. 307-342). Hillsdale, NJ: Erlbaum.

Stoel-Gammon, C. (2011). Relationships between lexical and phonological development in young children. Journal of Child Language, 38, 1-34.

Swanson, H. L., Zheng, X., \& Jerman, O. (2009). Working memory, short-term memory, and reading disabilities: A selective meta-analysis of the literature. Journal of Learning Disabilities, 42(3), 260-287.

Swingley, D., \& Aslin, R. N. (2000). Spoken word recognition and lexical representation in very young children. Cognition, 76(2), 147-166. http://dx.doi.org/10.1016/S00100277(00)00081-0.

Torgesen, J. K., \& Burgess, S. R. (1998). Consistency of reading-related phonological processes throughout early childhood: Evidence from longitudinal-correlational and instructional studies. Word recognition in beginning literacy, 161-188.

Van Goch, M. M., McQueen, J. M., \& Verhoeven, L. (2014). Learning phonologically specific new words fosters rhyme awareness in Dutch preliterate children. Scientific Studies of Reading, 18(3), 155-172.

Verhoeven, L. (2005). Screeningstest voor Taal-en Leesproblemen [Diagnostic test for language and literacy problems]. Arnhem, The Netherlands: Cito.

Verhoeven, L., Van Leeuwe, J., \& Vermeer, A. (2011). Vocabulary growth and reading development across the elementary school years. Scientific Studies of Reading, 15(1), $8-25$.

Verhoeven, L., \& Vermeer, A. (2006). Taaltoets Alle Kinderen. Handleiding [Language test for children]. Arnhem, The Netherlands: Cito.

Vloedgraven, J. M. T., Keuning, J., \& Verhoeven, L. (2009). Screeningsinstrument Beginnende Geletterdheid [Diagnostic instrument for emerging literacy]. Arnhem, The Netherlands: Cito.

Vloedgraven, J. M. T., \& Verhoeven, L. (2007). Screening of phonological awareness in the early elementary grades: An IRT approach. Annals of Dyslexia, 57(1), 33-50. http://dx.doi.org/10.1007/s11881-007-0001-2.

Wagner, R. K., \& Torgesen, J. K. (1987). The nature of phonological processing and its causal role in the acquisition of reading skills. Psychological bulletin, 101(2), 192.

Wagner, R. K., Torgesen, J. K., Laughon, P., Simmons, K., \& Rashotte, C. A. (1993). Development of young readers' phonological processing abilities. Journal of Educational Psychology, 85(1), 83.

White, K. S., \& Aslin, R. N. (2011). Adaptation to novel accents by toddlers. Developmental Science, 14(2), 372-384. http://dx.doi.org/10.1111/j.1467-7687.2010.00986.x.

White, K. S., \& Morgan, J. L. (2008). Sub-segmental detail in early lexical representations. Journal of Memory and Language, 59(1), 114-132. http://dx.doi.org/10.1016/j.jml. 2008.03.001.

Ziegler, J., \& Goswami, U. (2005). Reading acquisition, developmental dyslexia, and skilled reading across languages: A psycholinguistic grain size theory. Psychological Bulletin, 131(1), 3-29. http://dx.doi.org/10.1037/0033-2909.131.1.3. 